'Ye men of Israel, take heed to yourselves, what ye intend to do. And now I say unto you, if this counsel be of men it will come to naught; but if it be of God ye cannot overthrow it, lest haply ye be found fighting against God.' Shall I continue the quotation?-' and to Him they all agreed." "

\section{ABORANDI AS A GALACTAGOGUE.}

\author{
BY CHARLFS WESLEY ROOK, M.D., QUINCY, ILL.
}

Gentlemen of the Adams County, Ill., Medical Society: Permit me to again direct your attention for a few moments to the medicinal agent, jaborandi. In an article read in your presence, February I $\mathbf{r}$, I884, and published in the St. Louis Medical and Surgical Journal, April, I884, I gave some of my experience with jaborandi. In that paper was reported a case illustrating the galactagogue action of this agent.

The rase reported is briefly this:

“Mrs. J. B. S., A primipara, confined January I, I884. Labor natural and comparatively easy; child, female, average size and well developed. As the breasts secreted no milk the child was artificially nourished for a few days. The mother and child progressed well until January 6, when I was hastily summoned, and found Mrs. S. suffering severely from headache, high fever, the surface of the body being hot and dry, pulse $13 \circ$ per minute, and her breasts more tense and painful than they had yet been. Not having with me anything that would give her relief more quickly, or better meet the indications present than the extractum pilocarpi fluidum, she was given a $\eta$ xij dose, with directions for its repetition every half hour, until free diaphoresis was induced. The desired effect followed the third dose.

Simultaneously with the appearance of the perspiration and the increased flow of saliva, the milk began flowing in a stream from the left breast, and so continued during the active stage of diaphoresis. On the following day, while the skin was yet moist from the jaborandi received the evening previous, milk began flowing from the right breast."

At no subsequent period has that little child lacked nourishment. In the discussion following the reading of my paper, with reference to the case just mentioned, this question was asked: "Don't you think that the milk was just about ready to be secreted, and that its secretion would have occurred soon without the use of jaborandi?" I answered: "That, as the secretion was not established before, and occurring in such abundance upon the exhibition of jaborandi, I naturally attributed this sudden increase of functional activity to the jaborandi."

Since then, I have administered jaborandi in four cases in which there was a deficiency of milk secreted, with the intention of increasing the supply, and with results, in each case, nearly as marked as in the one reported. It is to neither of these cases that I ask your attention, but to another case in which I claim strong circumstantial evidence, if not proof positive, concerning the galactagogue action of jaborandi.
Mrs. L. S. M., who is in feeble health, weighing less than IIo pounds, is thirty-eight years of age, been married fifteen years, and has given birth to nine children, five of whom are now living. Mrs. M. furnished an abundance of milk for the nourishment of her first child, but on account of a failure of her supply of milk, the cause of which I could not learn, she was not able to nurse either of her next seven children, which in lieu of their mother's breast received the bottle. Of the seven there yet remaineth three little pale-faced children as livirg witnesses to the preservative power of the bottle.

January 3, I 885, I was called to see Mrs. M. On my arrival I found the labor just completed. An averagesized male child was born, and being yet attached to the cord, the latter was severed, and the mother and child made as comfortable as possible. Inquiry concerning the condition of the breasts was made, when the history as above noted was elicited. On physical examination of the mammary glands, no signs of functional activity could be observed within them. Directions were accordingly given for the artificial feeding of the child. I then told Mrs. M. that if her milk did not appear within a few days I would give her some medicine which would cause the secretion of milk in abundance. Three days after confinement, the mammary glands yet remaining inactive, she was ordered $m$ xxx doses of ext. jaborandi fl. every half hour, until free perspiration and salivation were produced. These effects were attained upon the exhibition of the fifth dose. The only noticeable effect upon the mammary glands was a slight enlargement. My patient, being very weak, was allowed an interval of one day in which to somewhat recover from the depressing effect of the free diaphoresis; then, as the condition of the mammary glands remained unchanged, she was given four $m \times x x$ doses at intervals of one-half hour, when the usual effect upon the skin and salivary glands was produced, while the following effect upon the mammary glands was noted: On this second exhibition of jaborandi the breasts rapidly filled, becoming tense and painful, but the pain and tension were soon relieved by the free flow of milk from each breast.

Here ended, for the present, any further necessity of artificially feeding the child.

Three weeks later I was called to see the child, and was informed that more milk was secreted than the child could nurse, the excess flowing freely from her breast. One week later I called in order to obtain a later report for my paper, and was surprised to find that the milk supply had failed and that the child was again nursing the bottle. I also learned that $\mathrm{my}$ patient had had, ever since the first appearance of the milk, a great fear that the supply would soon be exhausted, and wanting to do what she could to continue the secretion, had taken from the commencement, and without my advice, a daily $m \times x x$ dose of ext. jaborandi fl. The drug was ordered discontinued for two days, at which time, the mammary glands exhibiting no signs of their former activity, she was given three $m \times x x$ doses of ext. joborandi f., at intervals of half an hour, which produced free perspiration, salivation, lachrymation, enuresis, and, as we had 
hoped, a free lacteal discharge from each breast. The further use of the drug is forbidden. Nearly two weeks have elapsed since the last exhibition of ext. jaborandi fl., and my patient is secreting an abundance of milk. From my own experience with this medicinal agent, I am convinced that, in addition to the properties which make it a valuable diaphoretic, jaborandi has, first, a special stimulating effect upon the mammary secretions; second, the continued exhibition of the agent will be followed by functional exhaustion of the mammary glands; and third, a functionally exhausted mammary gland may, after an interval of rest, be again stimulated to activity by the proper exhibition of jaborandi.

Feb. 17 th, 1885 .

\section{COMBINED RECTAL AND INTRA-UTERINE IRRIGATOR.}

BY JNO. S. COLEMAN, M.D., AUGUSTA, Ga.

In the Medical Record of New York for May ro, 1879, I presented to the medical profession the

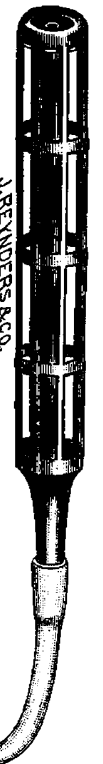
Metro Clyst. I now desire to call attention to a modification of this instrument which makes it available for the diseases of the rectum and surrounding pelvic structures. The instrument was skillfully constructed for me in April of last year by Messrs. Reynders \& Co., of New York city. It is of hard rubber, and consists of a cylindrical frame or cage traversed by a central tube. This arrangement insures the easy exit of the injected fluid. Any ordinary syringe can, by means of rubber tubing, be attached to it. My preference in the use of hot water is for the syphon.

Thanks to the genius of Dr. T. A. Emmet, we all now appreciate the indispensable value of hot water in inflammation and as a hæmostatic. Though I have not yet had an opportunity of testing the merits of this instrument in pelvic cellulitis or peritonitis, I feel confident that we will find it one of our most efficient measures in combating these serious and obstinate forms of disease. So far as I am informed, Dr. J. R. Chadwick was the first to advocate the rectal use of hot water in the treatment of pelvic inflammations. (Vide his able and interesting paper in the Transactions of the American Gynæcological Society for 1880 .) To me it promises much in acute prostatitis, rectitis, and internal hæmorrhoidal troubles.

I have had most gratifying success from its use in a case of puerperal endo-metritis, and in one of rectal ulcers.

Apomorphine in Asthma.-Dr. Weber, of Darmstadt, has used apomorphine, in doses of one-twelfth of a grain three times a day, in chronic asthma, with success.-Chi. Med. Journal.

\section{MEDICAL PROGRESS.}

\section{MATERIA MEDICA AND THERAPEUTICS.}

\section{Practical Remarks on the USe of Electricity in Mental Disease.}

Dr. A. DeWatteville writes, in The Journal of Mental Science, very encouragingly on the benefits of this treatment in mental disease, and considers the following as the chief indications to govern its use:

First-To promote the equilibrium of the cerebral innervation by acting directly on the nutrition of those centers which are deficient, functionally or organically, through molecular, vaso-motor or other influences. Experience shows we can do this, in some cases, by direct galvanization of the head and neck.

Second-To rouse up the peripheral and spinal innervation, and to indirectly restore their necessary equilibrium by supplying a deficiency in the different influxes upon which it partly depends. Here galvanization of the spine, and general faradisation (with the moist electrode or wire brush, according to the requirements of the case) will be of service.

Third-When the cerebral troubles are connected with some disturbance of the abdominal or pelvic viscera (visceral paræstheriæ, torpidity, and the like) to correct or mitigate the latter by the application of either current; or, better still, by galvano-faradisation. The value of electricity in visceral neurosis is very great, though hitherto unrecognized.

Fourth-To relieve certain symptoms as they arise according to the rules laid down in the usual treatises. It must not be forgotten, for instance, that general faradisation is a good tonic and excitant of general nutrition. In some cases, again, appropriate electrization acts as a promoter of sleep.

Meat Preparations.-Dr. Stutzer, Director of the Imperial Agricultural Chemical Laboratory, Bonn, Rhenish Prussia, has been, for several years (Midland Medical Miscellany), testing articles of food introduced into Germany for the use of invalids and children. In the tests applied to meat preparations, he first established the percentage of organic ingredients, mineral ingredients (salt) and water; and secondly, he tried, as far as feasible, to decompose the organic principles in them; determining, for instance, what proportion of nitrogen must be credited to the easily digested albumen and to peptone; and thus estimated, in the usual way, by multiplying by 6.25 (assuming that the constituent principles contained, on an average, 16 per cent of nitrogen) the quantity of albumen and peptones. As certain of the preparations contained no albuminous principles (fibrine) that were soluble in water, with these it became necessary to ascertain, by means of an additional digesting experiment, how much of the albuminous principles can be digested. Next, he took into consideration the quantity of nitrogen present in the form of meat bases (such as creatine, camine, etc.), because these meat bases, together 